\title{
ANALOGI WAKTU PARUH DAN KONSTANTA PELURUHAN (DISINTEGRASI) RADIOAKTIF
}

\author{
Dita Safitrianaz, Novyatun Latifah, Pia Yuningsih Saragih, Dandan Luhur \\ Saraswati \\ Program Studi Pendidikan Fisika, Universitas Indraprasta PGRI. \\ Email: ditasafitrianaz@gmail.com
}

Diterima: 15 Januari 2019. Disetujui: 10 Mei 2019.

\begin{abstract}
Abstrak
Telah dilakukan percobaan menggunakan gelas ukur untuk menganalogikan peluruhan radioaktif yang mudah dipahami. Tujuan dari percobaan ini untuk menentukan waktu paruh dan konstanta peluruhan dari analogi radioaktif. Metode penelitian ini dilakukan dengan variasi tinggi dari masing-masing lubang pada gelas ukur dengan ketinggian $13 \mathrm{~cm} ; 22 \mathrm{~cm} ; 28 \mathrm{~cm} ; 31,5 \mathrm{~cm}$ dan $34,5 \mathrm{~cm}$ yang dilakukan pengulangan sebanyak 5 kali untuk setiap lubang. Dari hasil percobaan diperoleh waktu paruh (T) dari masing-masing lubang $\mathrm{T}_{1}=0 \mathrm{~s}, \mathrm{~T}_{2}=14,656 \mathrm{~s}, \mathrm{~T}_{3}=17,532 \mathrm{~s}, \mathrm{~T}_{4}=18,416 \mathrm{~s}, \mathrm{~T}_{5}=21,798 \mathrm{~s}$ dengan konstanta peluruhan $(\lambda)$ dari masing-masing lubang $\lambda_{1}=0 \mathrm{~s}^{-1}, \lambda_{2}=$ $0,0472 \mathrm{~s}^{-1}, \lambda_{3}=0,0395 \mathrm{~s}^{-1}, \lambda_{4}=0,0376 \mathrm{~s}^{-1}, \lambda_{5}=0,0317 \mathrm{~s}^{-1}$. Berdasarkan hasil percobaan tersebut dapat disimpulkan bahwa hubungan antara waktu paruh dengan konstanta peluruhan berbanding terbalik karena semakin lama waktu paruh yang didapatkan maka semakin kecil nilai konstanta peluruhan.
\end{abstract}

Kata Kunci: waktu paruh, konstanta peluruhan, radioaktif.

\begin{abstract}
The purpose of this experiment is to determine the half-life and decay constants of radioactive analogies. The method of this research is carried out with a high variation of each hole in a measuring cup with a height of $13 \mathrm{~cm}$; $22 \mathrm{~cm} ; 28 \mathrm{~cm} ; 31.5 \mathrm{~cm}$ and $34.5 \mathrm{~cm}$ which are repeated 5 times for each hole. From the experimental results obtained the half-life $(T)$ of each hole $T_{1}=0 \mathrm{~s}$, $T_{2}=14,656 \mathrm{~s}, T_{3}=17,532 \mathrm{~s}, T_{4}=18,416 \mathrm{~s}, T_{5}=21,798 \mathrm{~s}$ with the decay constant ( $\lambda$ ) of each hole $\lambda_{1}=0 s^{-1}, \lambda_{2}=0,0472 s^{-1}, \lambda_{3}=0,0395 s^{-1}, \lambda_{4}=$ $0,0376 \mathrm{~s}^{-1}, \lambda_{5}=0,0317 \mathrm{~s}^{-1}$. Based on the results of these experiments it can be concluded that the relationship between half-life and decay constant is inversely proportional because the longer half-life obtained, the smaller the decay constant value.
\end{abstract}

Keywords: half-life, decay constant, radioactive.

\section{PENDAHULUAN}

Pembelajaran yang diterapkan abad 21 menuntut pembelajaran berpusat kepada peserta didik (Nyeneng, 2018). Trowbridge mengatakan bahwa fisika pada hakekatnya melibatkan dimensi produk berupa kumpulan teori yang telah teruji kebenarannya, dimensi produknya berupa serangkaian 
Safitrianaz., Latifah., Saragih., Saraswati. - Analogi Waktu Paruh dan ...

kegiatan yang harus dilakukan untuk memperoleh pengetahuan dan gejalagejala alam sebagai metode ilmiah (Muzana, 2018).

Fisika bukan sekadar pelajaran teori dimana manfaatnya tidak dapat dirasakan oleh masyarakat (Saraswati \& Putri, 2018). Pembelajaran Fisika Modern ditujukan untuk mendidik peserta didik agar mampu mengembangkan observasi dan eksperimentasi. Hal ini didasari oleh tujuan fisika yaitu mengamati, memahami dan memanfaatkan gejalagejala alam yang melibatkan zat dan energi. Kemampuan observasi dan eksperimentasi ini lebih ditekankan untuk melatih kemampuan berpikir eksperimental mencakup tata laksana percobaan dengan mengenal peralatan yang digunakan dalam pengukuran baik di dalam laboratorium maupun di alam sekitar kehidupan (Suparjo, 2014).

Namun kenyataannya menunjukkan bahwa terdapat konsepkonsep fisika modern tidak mungkin dapat dipahami peserta didik hanya dengan membaca buku dan menghafal rumus-rumus. Hal ini dikarenakan peserta didik hanya melakukan proses pembelajaran di kelas, tidak dilengkapi dengan proses eksperimen. Oleh karena itu salah satu solusi untuk mengatasi masalah tersebut adalah memanfaatkan alat dan bahan di sekitar lingkungan untuk dijadikan alat eksperimen sederhana, salah satunya mengenai waktu paruh radioaktif. Tujuan dari eksperimen ini adalah untuk menentukan waktu paruh dan konstanta disintegrasi dari analogi radioaktif.

Radioaktif adalah gejala pemancaran radiasi gelombang elektromagnetik atau partikel secara spontan yang berasal dari perubahan inti atom. Bahan yang mempunyai gejala ini disebut bahan radioaktif. Perubahan dalam inti atom mengakibatkan perubahan suatu unsur ke unsur lain, peristiwa ini dinamakan dengan peluruhan radioaktif (Kurniawan, 2003). Pada tahun 1903, Ernest Rutherford mengemukakan bahwa radiasi yang dipancarkan zat radio aktif dapat dibedakan atas dua jenis berdasarkan muatannya, radiasi yang berrnuatan positif dinamai sinar alfa, dan yang bermuatan negative diberi nama sinar beta (Arma, 2004). 
Safitrianaz., Latifah., Saragih., Saraswati. - Analogi Waktu Paruh dan ...

Dalam radioaktivitas, aktivitas radioaktif (A) merupakan peluruhan (disintegrasi) yang dilakukan sejumlah zat radioaktif setiap satuan waktu. Aktivitas juga menunjukkan laju peluruhan bahan radioaktif. Satuan aktivitas zat radioaktif untuk tingkat aktivitas rendah yaitu Becquerel (Bq), sedangkan untuk aktivitas zat radioaktif tingkat aktivitas sangat tinggi satuannya adalah Curie (Ci). Aktivitas radioaktif hanya menunujukkan jumlah inti radioaktif yang melakukan peluruhan, tetapi tidak menunjukkan jumlah radiasi yang dipancarkan karena setiap kali melakukan peluruhan, zat radioaktif dapat memancarkan lebih dari satu macam radiasi (Kristiyanti, 2017).

Semakin besar aktivitas maka semakin banyak inti yang meluruh per satuan waktu (Swandi, 2014). Suparjo (2014) menyatakan Aktivitas bahan radioaktif besarnya tergantung dari banyaknya zat radio aktif $(\mathrm{N})$. Aktivitas juga menunjukkan laju peluruhan bahan radio aktif, sehingga dapat ditulis:

$$
A(t)=\left[-\frac{d N}{d t}\right]
$$

tanda (-) menunjukkan $\mathrm{N}$ berkurang terhadap waktu. Hubungan antara aktivitas awal (Ao) dengan aktivitas sesudah $t$ (At) adalah:

$$
\mathrm{A}_{\mathrm{t}}=\mathrm{A}_{0} \mathrm{e}^{-\lambda \mathrm{t}}
$$

(Khaerani,2007).

Hasil persamaan akhirnya diperoleh: $\mathrm{N}=\mathrm{N}_{0} \mathrm{e}^{-\lambda t}$ dengan mengalikan $\lambda$ pada masing-masing ruas, sehingga didapatkan bahwa $\mathrm{A}=$ $\mathrm{A}_{0} \mathrm{e}^{-\lambda \mathrm{t}}$, dimana $\lambda$ merupakan konstanta peluruhan, $N$ sebagai jumlah atom suatu bahan radioaktif pada suatu waktu, $N_{0}$ sebagai jumlah atom mula-mula, $t$ sebagai waktu peluruhan dalam satuan sekon, $e$ merupakan bilangan natural bernilai 2,71828 (Sasongko,2010)

Sedangkan waktu paruh adalah waktu yang dibutuhkan suatu inti radioaktif menjadi separuh atau setengah dari inti mula-mula. Untuk waktu paruh yang terjadi pada radioaktif alami tidak terpengaruh oleh faktor-faktor alam seperti perubahan situasi lingkungan (cuaca, suhu, tekanan, dll) maupun peristiwaperistiwa kimia yang lain. Sehingga aktivitasnya $A=\frac{1}{2} A$ 。 (Suparjo, 
Safitrianaz., Latifah., Saragih., Saraswati. - Analogi Waktu Paruh dan ...

2014), kemudian didapat nilai waktu paruh peluruhannya menjadi:

$$
\mathrm{T}_{1 / 2}=\frac{\operatorname{In} 2}{\lambda}=\frac{0,693}{\lambda}
$$

(Krane, 2014).

Jika $\lambda$ tiadak diketahui nilainya, maka dapat menggunakan rumus:

$\mathrm{T}=\frac{t}{n}$

Sehingga didapat nilai konstanta disintegrasinya:

$\lambda=\frac{0,693}{T_{1 / 2}}$

Berdarsarkan persamaanpersamaan diatas maka nilai waktu paruh peluruhannya akan berbanding terbalik dengan nilai konstanta disintegrasinya.

\section{METODE}

Alat eksperimen ini dibuat untuk menganalogikan peluruhan zat radioaktif dengan menghitung lamanya waktu paruh dan menghitung konstanta disintegrasi (peluruhan) nya. Metode yang digunakan dalam penelitian ini adalah metode eksperimen menggunakan gelas ukur1 liter yang dibuat dengan model tabung Torricelli. Gelas ukur yang kami gunakan berbahan plastik dikarenakan untuk memudahkan pada saat pelubangan. Stopwatch untuk mencatat waktu peluruhannya, air sebagai analogi zat radioaktif dan meteran untuk mengukur jarak antar lubang. Langkah-langkah penelitian ini menggunakan enam tahap, yaitu Concept (konsep), Design (perancangan), Material collecting (pengumpulan bahan), Assembly (pembuatan), Testing (pengujian), dan Evaluation (evaluasi).(Basyari,2012)

Pada tahap concept dilakukan penentuan bahan gelas ukur yang akan digunakan. Tahap design adalah tahap membuat spesifikasi secara rinci mengenai arsitektur proyek gaya, pembuatan alat eksperimen analogi waktu paruh menggunakan desain tabung Torricelli. Desain alat eksperimen ditunjukkan pada gambar 1.

Tahap material collecting adalah tahap pengumpulan bahan yang diperlukan dalam pembuatan alat eksperimen, bahan yang digunakan pada alat eksperimen adalah air sebagai analogi zat radioaktifnya.

Tahap assembly adalah tahap dimana seluruh alat dan bahan telah dibuat, perancagan alat telah dibuat pada tahap design. 
Safitrianaz., Latifah., Saragih., Saraswati. - Analogi Waktu Paruh dan ...

Tahap testing dilakukan setelah memperbaiki atau menambahkan agar tahap pembuatan selesai. Tahap alat eksperimen layak digunakan testing adalah tahap pengujian alat dengan semestinya.

untuk pengambilan data.

Setelah semua langkah-langkah

Tahap evaluation adalah tahap penelitian dilakukan maka gambar peninjauan kembali untuk alatnya seperti pada gambar 2.

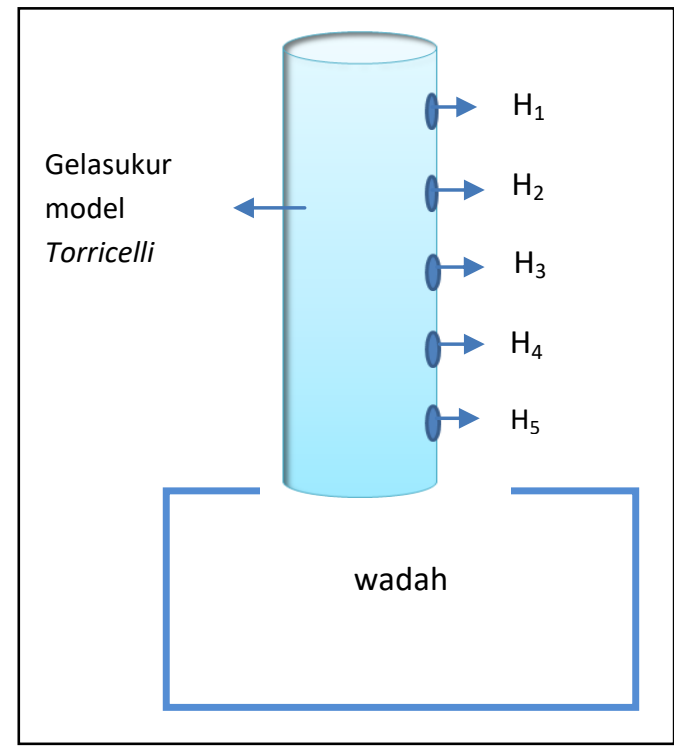

Gambar 1. Desain Alat Eksperimen Analogi Waktu Paruh dan Konstanta Peluruhan Radioaktif

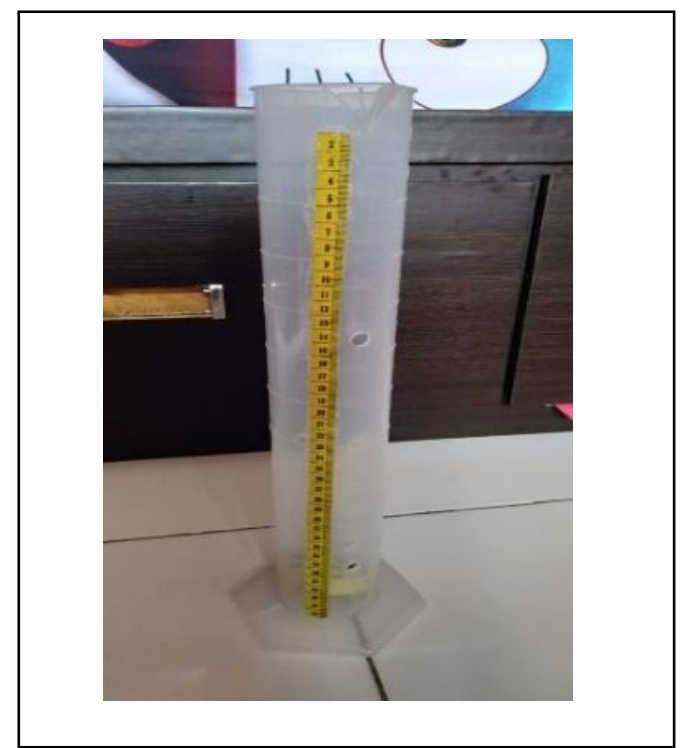

Gambar 2. Alat Eksperimen Analogi Waktu Paruh dan Konstanta Peluruhan Radioaktif 
Safitrianaz., Latifah., Saragih., Saraswati. - Analogi Waktu Paruh dan ...

Pengujian dilakukan dengan cara mengukur jarak dari masing-masing lubang menggunakan meteran. Lalu tutup semua lubang dan isi penuh gelas tersebut dengan air. Kemudian buka lubang kebocoran $\mathrm{H} 1$, amati pergerakan turun permukaan air dari botol. Ketika permukaan air sampai pada tanda pertama $\left(\mathrm{H}_{1}\right)$, mulailah pengukuran waktu $(\mathrm{t}=0)$ dan seterusnya setiap permukaan air sampai pada tiap-tiap lubang kebocoaran (tanda), catatlah waktunya. Lakukan percobaan ini sampai lima kali untuk setiap lubang yang sama.

\section{HASIL DAN PEMBAHASAN}

Berdasarkan percobaan yang telah dilakukan, maka didapat hasil percobaan seperti pada tabel 1 .

1. Tabel percobaan pada lubang $\mathrm{H}_{1}=$ $13 \mathrm{~cm}$

\begin{tabular}{|c|c|}
\hline Percobaan ke- & $\mathrm{t}$ (sekon) \\
\hline 1 & 0 \\
\hline 2 & 0 \\
\hline 3 & 0 \\
\hline 4 & 0 \\
\hline 5 & 0 \\
\hline$\sum$ & 0 \\
\hline
\end{tabular}

Berdasarkan datatabel percobaan pada lubang $\mathrm{H}_{1}=13$ cmmaka diperoleh waktu paruh $\left(\mathrm{T}_{1 / 2}\right)$ menggunakan rumus:

$\mathrm{T}_{1 / 2}=\frac{\sum t}{n}=\frac{0}{5}=0$ sekon

Sedangkan untuk menghitung besar konstanta peluruhan atau disintegrasidapat menggunakan rumus:

$$
\lambda=\frac{0,693}{T_{1 / 2}}=\frac{0,693}{5}=0 \mathrm{~s}^{-1}
$$

2. Tabel percobaan pada lubang $\mathrm{H}_{2}=$ $22 \mathrm{~cm}$

\begin{tabular}{|c|c|}
\hline Percobaan ke- & $\mathrm{t}$ (sekon) \\
\hline 1 & 15,58 \\
\hline 2 & 12,64 \\
\hline 3 & 15,06 \\
\hline 4 & 14,88 \\
\hline 5 & 15,12 \\
\hline$\sum$ & 73,28 \\
\hline
\end{tabular}

Berdasarkan datatabel percobaan pada lubang $\mathrm{H}_{2}=22 \mathrm{~cm}$ maka diperoleh waktu paruh $\left(\mathrm{T}_{1 / 2}\right)$ menggunakan rumus:

$\mathrm{T}_{1 / 2}=\frac{\sum t}{n}=\frac{73,28}{5}=14,656$ sekon

Sedangkan besar konstanta peluruhan atau disintegrasi dapat diperoleh menggunakan rumus :

$\lambda=\frac{0,693}{T_{1 / 2}}=\frac{0,693}{73,28}=0,0472 \mathrm{~s}^{-1}$

3. Tabel percobaan pada lubang $\mathrm{H}_{3}=$ $28 \mathrm{~cm}$ 
Safitrianaz., Latifah., Saragih., Saraswati. - Analogi Waktu Paruh dan ...

\begin{tabular}{|c|c|}
\hline Percobaan ke- & $\mathrm{t}$ (sekon) \\
\hline 1 & 16,70 \\
\hline 2 & 17,34 \\
\hline 3 & 17,21 \\
\hline 4 & 17,55 \\
\hline 5 & 18,86 \\
\hline$\sum$ & 87,66 \\
\hline
\end{tabular}

$\mathrm{T}_{1 / 2}=\frac{\sum t}{n}=\frac{92,08}{5}=18,416$ sekon

Sedangkan besar konstanta peluruhan atau disintegrasi dapat diperoleh menggunakan rumus :

Berdasarkan data tabel percobaan pada lubang $\mathrm{H}_{3}=28 \mathrm{~cm}$ maka diperoleh waktu paruh $\left(\mathrm{T}_{1 / 2}\right)$ menggunakan rumus:

$\mathrm{T}_{1 / 2}=\frac{\sum t}{n}=\frac{87,66}{5}=17,532$ sekon

Sedangkan untuk menghitung besar konstanta peluruhan atau disintegrasi dapat menggunakan rumus:

$$
\begin{aligned}
\lambda=\frac{0,693}{T_{1 / 2}} & =\frac{0,693}{17,532} \\
& =0,0395 \mathrm{~s}^{-1}
\end{aligned}
$$

4. Tabel percobaan pada lubang $\mathrm{H}_{4}=$ $31,5 \mathrm{~cm}$

\begin{tabular}{|c|c|}
\hline Percobaan ke- & $\mathrm{t}$ (sekon) \\
\hline 1 & 18,14 \\
\hline 2 & 18,32 \\
\hline 3 & 19,10 \\
\hline 4 & 18,47 \\
\hline 5 & 18,05 \\
\hline$\sum$ & 92,08 \\
\hline
\end{tabular}

Berdasarkan data tabel percobaan pada lubang $\mathrm{H}_{4}=31,5 \mathrm{~cm}$ maka diperoleh waktu paruh $\left(\mathrm{T}_{1 / 2}\right)$ menggunakan rumus :

$$
\lambda=\frac{0,693}{T_{1 / 2}}=\frac{0,693}{92,08}=18,416 s^{-1}
$$

5. Tabel percobaan pada lubang $\mathrm{H}_{4}=$ $31,5 \mathrm{~cm}$

\begin{tabular}{|c|c|}
\hline Percobaan ke- & $\mathrm{t}$ (sekon) \\
\hline 1 & 21,12 \\
\hline 2 & 21,65 \\
\hline 3 & 21,20 \\
\hline 4 & 22,65 \\
\hline 5 & 22,37 \\
\hline$\sum$ & 108,99 \\
\hline
\end{tabular}

Berdasarkan data tabel percobaan pada lubang $\mathrm{H}_{4}=31,5 \mathrm{~cm}$ maka diperoleh waktu paruh $\left(\mathrm{T}_{1 / 2}\right)$ menggunakan rumus :

$\mathrm{T}_{1 / 2}=\frac{\sum t}{n}=\frac{108,99}{5}=21,798$ sekon

Sedangkan besar konstanta peluruhan atau disintegrasi dapat diperoleh menggunakan rumus :

$$
\lambda=\frac{0,693}{T_{1 / 2}}=\frac{0,693}{21,798}=0,0317 s^{-1}
$$

Pada percobaan ini, kami menggunakan gelas ukur berbahan plastic untuk memudahkan pada saat pelubangan. Pelubangan dilakukan 
Safitrianaz., Latifah., Saragih., Saraswati. - Analogi Waktu Paruh dan ...

menggunakan mata bor berukuran 8 cm. Kami menggunakan meteran untuk memudahkan melihat ketinggian air saat meluruh dan stopwatch untuk menghitung waktu peluruhannya. Kami melakukan lima kali pengulangan pengambilan data untuk setiap lubang dengan selisih jarak antar lubang menggunakan kelipatan tiga. Setiap kali melakukan pengulangan pengambilan data di setiap lubang, air selalu diisi penuh melebihi lubang pertama.

Bahan yang digunakan adalah air bening. Ketika gelas ukur akan diisi dengan air, maka setiap lubang ditutup menggunakan penutup lubang agar air tidak mengalir keluar. Setelah itu barulah dilakukan pengisian air pada gelas ukur hingga penuh. Pada saat pengambilan data hanya lubang yang bersangkutan saja yang dibuka dan gelas ukur dalam keadaan terbuka (tanpa penutup). Kemudian aktifkan stopwatch untuk menghitung lamanya air mengalir keluar dari lubang tersebut.

Pada lubang pertama dilakukan lima kali pengulangan percobaan dan total waktu yang dibutuhkan untuk meluruh adalah 0 sekon, artinya tidak ada peluruhan yang terjadi dan juga tidak ada nilai konstanta peluruhannya. Pada percobaan pertama di lubang kedua, air tetap diisi dalam keadaan penuh melebihi lubang pertama. Sehingga didapat lama air mengalir keluar selama 15,58 sekon, kemudian percobaan kedua selama 12,64 sekon, percobaan ketiga selama 15,06 sekon, percobaan keempat selama 14,88 sekon dan percobaan kelima selama 15,12 sekon. Hal ini dikarenakan jarak antar lubang pertama dengan lubang kedua cukup jauh sehingga mengakibatkan waktu peluruhan pada lubang kedua bervariasi. Maka besar nilai konstanta peluruhan atau disintegrasinya sebesar $0,0472 \mathrm{~s}^{-1}$.

Lubang ketiga pada percobaan pertama didapat lama air mengalir keluar selama 16,70 sekon. Kemudian pada percobaan kedua selama 17,34 sekon. Percobaan ketiga selama 17,21 sekon. Percobaan keempat selama 17,55 sekon dan percobaan kelima selama 18,86 sekon.

Maka besar nilai konstanta peluruhan atau disintegrasinya sebesar $0,0395 \mathrm{~s}^{-1}$. 
Safitrianaz., Latifah., Saragih., Saraswati. - Analogi Waktu Paruh dan ...

Lubang keempat pada percobaan pertama didapat air mengalir keluar selama 18,14 sekon. Kemudian pada percobaan kedua selama 18,32 sekon. Percobaan ketiga selama 19,10 sekon. Percobaan keempat selama 18,47 sekon dan percobaan kelima selama 18,05 sekon. Maka besar nilai konstanta peluruhan dan disintegrasinya sebesar $18,416 \mathrm{~s}^{-1}$.

Lubang kelima pada percobaan pertama didapat air mengalir keluar selama 21,12 sekon. Pada percobaan kedua selama 21,65 sekon. Pada percobaan ketiga selama 21,65 sekon. Pada percobaan keempat selama 22,65 sekon dan pada percobaan kelim aselama 22,37 sekon. Hal ini dikarenakan jarak antar lubang keempat dan kelima cukup dekat, sehingga besar nilai konstanta peluruhan dan disintegrasinya sebesar $0,0317 \mathrm{~s}^{-1}$.

\section{Ucapan Terima Kasih}

Penulis mengucapkan terima kasih kepada laboratorium fisika Universitas Indraprasta PGRI karena telah memberikan izin penggunaan tempat untuk mendukung penelitian ini.

\section{KESIMPULAN DAN SARAN}

Dari hasil percobaan diperoleh bahwa waktu paruh dari masing-masing percobaan yaitu: $T$ percobaan $1=0 \mathrm{~s}$, $\mathrm{T}$ percobaan $2=14,656 \mathrm{~s}, \mathrm{~T}$ percobaan $3=17,532 \mathrm{~s}$, T percobaan $4=18,416 \mathrm{~s}$, dan $\mathrm{T}$ percobaan $5=$ $21,798 \mathrm{~s}$.

Konstanta disintegrasi dari masing-masing percobaan yaitu: $\lambda$ percobaan $1=0 \mathrm{~s}^{-1}, \lambda$ percobaan $2=$ $0,0472 \mathrm{~s}^{-1}, \lambda$ percobaan $3=0,0395^{\mathrm{s}-1}$, $\lambda$ percobaan $4=0,0376 \mathrm{~s}^{-1} \mathrm{dan} \lambda$ percobaan $5=0.0317 \mathrm{~s}^{-1}$.

Berdasarkan hasil yang didapat melalui ekperimen, sebaiknya alat pada penelitian ini dikembangkan lebih baik lagi sehingga media pembelajaran lebih menarik dan mendapatkan hasileksperimen yang lebih akurat.

\section{DAFTAR PUSTAKA}

Arma, A. J. A. (2004). Zat Radio Aktif dan Penggunaan Radio Isotop Bagi Kesehatan. Universitas Sumatra Utara, Medan.

Basyari, A., Sunaryo, S., \& Iswanto, B. H. (2012). Pengembangan Media Pembelajaran Fisika Berbasis Adobe Flash untuk Menjelaskan Fisika Inti dan Radioaktivitas Untuk SMA Kelas 
Safitrianaz., Latifah., Saragih., Saraswati. - Analogi Waktu Paruh dan ...

XII. In Prosiding Seminar Nasional Fisika (E-Journal)(Vo. 1,pp. 116-120).

Khaerani, N., Azam, M., Firdausi, K. S., \& Soeleman, S. (2007). Penentuan kandungan unsure krom dalam limbah tekstil dengan metode analisis pengaktifan neutron. Berkala Fisika, 10(1), 35-43.

Krane, Kenneth S. (2014). Fisika Modern. Jakarta: Penerbit Universitas Indonesia (UI Press).

Kristiyanti, K., Imran, W. Z., \& Yuniarsari, L. (2017). Analisis Waktu Paruh Peluruhan Terhadap Persyaratan Dosis Radio isotop untuk Pemeriksaan Gondok. Prima-Aplikasi dan Rekayasa dalam Bidang Iptek Nuklir, 6(2), 371-375.

Kurniawan, Y. B. (2003). Analisis Kandungan Unsur Merkuri $(\mathrm{Hg})$ dalam Tanah Pertanian Menggunakan Metode Analisis Pengaktifan Neutron (APN) (Doctoral dissertation, Universitas Sebelas Maret).

Nyeneng, I. D. P., \& Suana, W. (2018). Pengembangan Perangkat Flipped Classroompada Mata Pelajaran Fisika SMA. Jurnal Pendidikan Fisika, 6(2), 159-174.

Muzana, S. R. (2018). Penerapan Laboratorium Virtual Terhadap
Hasil Belajar Fisika Pada Materi Rangkaian Arus Boalk-Balik Siswa Kelas XII SMA Negeri Abulyatama. Jurnal Pendidikan Fisika, 6(1), 34-42.

Saraswati, D. L., \& Putri, D. A. (2018). Architecture of Atwood Machine Props with Sensor-based Passive Infrared. Indonesian Review of Physics, 1(1), 15-18.

Sasongko, D. P., \& Tresna, W. P. (2010). Identifikasi unsur dan kadar logam berat pada limbah pewarna batik dengan metode analisis pengaktifan neutron. Jurnal Ilmu Pengetahuan dan Teknologi Telaah, 2(1), 22-27.

Suparjo, S. (2014). Menentukan Waktu Paroh dan Konstanta Analogi Disintegrasi Radioaktif dengan Alat Peraga Pembelajaran Analogi Disintegrasi Radioaktif dari Botol Plastik. Jurnal Materi dan Pembelajaran Fisika, 4(1).

Swandi, A., Hidayah, S. N., \& Irsan, L. J. (2014). Pengembangan Media PembelajaranLaboratorium Virtual untuk Mengatasi Miskonsepsi Pada Materi Fisika Inti di SMAN 1 Binamu, Jeneponto. Jurnal Fisika Indonesia, 18(52)., 20-24. 